UDC 614.48

\title{
BIO-PATHOGENS AS A SIGNIFICANT HEALTH RISK FACTOR AND THEIR CONTROL IN ENVIRONMENT \\ OR DESINFECTING "RISKS IN THE HONORABLE MISSION" OF COMBAT AGAINST INFECTIOUS DISEASES
}

\author{
N.V. Shestopalov, M.G. Shandala \\ Federal Budgetary Scientific Institution "Research Institute of Desinfectology” under Rospotrebnadzor, \\ Sechenov First Moscow State Medical University under RF Ministry of Health \\ Moscow, Russia
}

Due to the significant proportion of infectious diseases in the general population morbidity, the article explains the need to attract more attention to the study biological pathogens in the environment as a significant health risk factor, as well as the development of a specific methodology for its evaluation within the antimicrobial protection frames. Disinfection based on the use of antimicrobial agents for the epidemiological purposes is an important element of this system, that is why the article deals with the generation of main factors of individual and population risk of infectious diseases. The contingency of the disinfection activity with health risks is formulated: the lack of its effectiveness, on the one hand, and the lack of biocidal selectivity of disinfectants used, on the other. So, there are risks of injury both in case of the non-use (epidemiological risk) and in case of incorrect use (toxic and hygienic risks) of disinfection measures, which, therefore, require the development and use of a new concept - "Risk vs. Risk".

Key words: biopathogens, antimicrobial protection, infectious diseases, disinfection activity, microbial resistance, disinfection risks.

One of the most important indicators of individual and public health is infectious disease incidence the share of which in the total incidence reaches $50 \%$ while the share of infections in the total death rate is $25 \%$, and in child death rate - up to $60 \%$ [4].

Clearly, not only chemical and physical pathogenic agents in the environment, but also biological pathogens - agents of infectious and parasitic diseases - require special attention as serious health risk factors. Obviously, for this reason, G.G. Onischenko, A.Yu. Popova, N.V. Zaitseva et al [7] and other researchers emphasize the importance of determining the reasons of and identifying the conditions for the spread of infectious diseases among the authorities of Rospotrebnadzor.

However, our thorough review of the pub lications in the "Health Risk Analysis" ("Analiz riska zdoroviu") journal and the resolution of the All-Russian Conference "Today's Issues of Safety and Health Risk Analysis under Exposure to Environmental Factors" (May 21-23, 2014, Perm) has shown that biological pathogens in the environment are not yet in the focus of risk-metrological attention.

According to the text of the above resolution published in the journal and during "the discussion of the current issues of public health safety under exposure to environmental factors..." and when determining "the priority areas of improving the services in terms of health risk mitigation...", they are likely to have not been mentioned as significant risk factors [8].

In the meantime, people are being con-

\footnotetext{
Shestopalov N.V., Shandala M.G., 2014

Shestopalov Nikolai Vladimirovich (Moscow, Russia) - Doctor of Medical Sciences, Professor; Director of the Scientific Research Institute of Disinfectology Under Rospotrebnadzor (117246, Moscow, Nauchniy proezd, 18; e-mail: info@niid.ru; telephone: +7 (495) 332-01-01).

Shandala Mikhail Georgievich (Moscow, Russia) - academician of the Russian Academy of Sciences, Doctor of Medical Sciences, Professor; senior research associate, the Scientific Research Institute of Disinfectology Under Rospotrebnadzor (117246, Moscow, Nauchniy proezd, 18;; e-mail: info@ niid.ru; retelephone: +7 (495) 332-01-10).
} 
stantly exposed to various biopathegens which calls for a careful assessment of the presence and level of health hazard associated with their impact including functional disorders and clinical development of corresponding infectious diseases [1].

Since biopathogens differ from pathogenic chemical and physical environmental factors in terms of impact mechanisms and nature, health risk assessment procedure, namely identification and assessment of probable health risks associated with various biopathogens requires thorough study.

Such risk assessment aims at fighting infectious diseases; the success of this struggle depends on the efficiency of the System of antimicrobial protection. Unfortunately, such System requires further development and implementation.

Nevertheless, it is obvious that disinfection including the use of antimicrobial measures is an important link in this chain. The measures include:

- sanitary measures to protect the environment from pollution by pathogenic micro, including decontamination of waste and waste water prior to their release to the environment;

- disinfection measures to destroy or inactivate pathogens that are about to enter the environment (preventive disinfection), or already populate the environment, including the surface of the body, clothing, etc. protected contingents (focal disinfection, sterilization);

- health measures to eliminate (including, by destroying) the potential vectors and carriers of infectious pathogens (disinfestation, disacaridisation, vermin, etc.)

The above protective measures are used primarily to fight public health risks associated with infectious diseases.

As for individual risks of infectious diseases, they are comprised of various interconnected factors; additionally (foremost!), such risk depends on the type (characteristics) of pathogenic microbe, their routes and mechanisms of entry, prevalence and development in a macroorganism, and the physical powers of the latter to fight the pathogens. These factors combined with the medical treatment influence the nature, symptoms and outcome of an infectious disease

The central factor in these processes is such an important biological property of a pathogenic microorganism as its sensitivity/resistance to the attack of external factors: environment, phylactic powers of a macroorganism as well as the medicaments [4].
Moreover, the resistance of microbiopathogens is an important factor of the development (meaning - assessment) of health risks also in connection with the development and use of disinfectants - antimicrobial agents aimed for elimination or inactivation of pathogenic microorganisms in the environment as health risk factors.

Disinfection aimed at mitigating health risks (as well as in the medical field in general) is based on the following principle: "do not do harm". Harm prevention when carrying out disinfecting activities requires understanding and exclusion of potential hazards which are directly or indirectly associated with the activities.

The biggest hazard associated with disinfection is its ineffectiveness (or insufficient effectiveness). For example, ineffective local disinfection can cause a disease outbreak [2].

But potential hazard risks related to disinfection go beyond that. There are four possible dangers associated with disinfection:

- Damage to human health and the patients of healthcare facilities;

- Damage to the health of the disinfection service personnel and medical institutions;

- Damage to the environment, natural and urban ecosystems;

- Technological and economic costs of damage to tools, equipment, etc.

The analysis of such risks shows that their causes lie, on the one hand, in failure to provide a necessary level of efficiency of disinfection, and on the other hand - toxic properties, and irritating and corroding effects associated with disinfectants.

Consequently, disinfection can bear the following two-way health risks:

On the one hand, these are the risks from non-use of disinfection and associated risk of new cases of outbreaks or even epidemiological incidence of infectious diseases.

Epidemiology has developed approaches to assessing the level of an epidemic depending on the circulation of an epidemic agent in the population and the environment, and has accumulated some experience in this area [1]. For this reason, a direct health damage in the form of infectious diseases (or risk of such damage) following non-use of disinfection can be assessed with a certain degree of approximation. The situation is much worse (if not to say - poor) with the assessment of risks of indirect health damage resulting from nonuse of disinfection aimed at preventing people's contact with the arthropods and rodents, not only 
due to the related epidemiological risks. Such contact can cause noninfectious diseases, for example, 'domestic allergy', and even bronchial allergy resulting from contact with dust mites, etc.

Since health as defined by the WHO is not only the absence of disease or infirmity, but also a state of complete physical, mental and social wellbeing, domestic insects and rodents do damage (bring health risks) not only directly, but also indirectly - through financial damage (food contamination and destruction, etc.), through creating emotional, psychological, and domestic discomfort, etc.

On the other hand, there is risk (potential harm) associated with incorrect use of disinfectants (for example, chemical agents) since they are biocidal agents developed specially for the destruction (elimination) of various life forms (targets of disinfection) - from pathogenic microbes to epidemiologically significant arthropods (insects) and even mammals (rodents).

Biocidal properties of such agents are provided by the biologically active reactants with toxic properties which are not only selective meaning antimicrobial, insecticidal, etc. but also potentially hazardous to human [10].

This necessitates scientific development and implementation of hygienic activities aimed at ensuring safe use of disinfectants.

Potential negative effects can "trigger" a chain of various biological responses - adaptive, compensatory, and pathological, quickly alternating or remaining at a certain stage depending on the nature, power, and duration of effect of a factor.

For this reason, it is possible to develop approaches to quantification of risks - probability of consequences of various health factors, and, subsequently, scientific justification of various environmental regulations [3].

This task is more challenging when disinfection is needed inside a home, as compared to the 'regular' contaminants of the environment or workplace, because when conducting disinfection, it is optimal to have a chemical agent in the environment at a level that would provide the desired local effect (antimicrobial, insecticidal, etc.) without harming human health.

In this regard, household chemicals (including disinfectants) are very similar to agricultural pesticides, nuclear energy, etc. In the case of their use, potential harm (unfortunately) to public health is opposed to the obvious social (including medical, healthcare) benefit from such use (the famous 'risk-effect' concept) [7].

Meanwhile, disinfectants require the development and use of the "risk versus risk" concept, since disinfection bears a possibility of damage both in the non-use and use of preventive disinfection. Therefore, the main objective is to provide a variety of protective measures, including the traditional ways and means: mechanization of disinfection work, use of personal protective equipment, strict adherence to recommended treatment modes, other organizational, technological, technical and other measures.

The most radical area of work here is the application of specific biologically active chemicals and the development and application on their basis of disinfectants that have the highest selective properties (maximal risk) of specific toxic effect at target objects against the minimal risk of toxicity for people. In other words, they provide the highest specific disinfection anti-epidemic efficiency along with maximal hygienic and ecological safety [12].

Since health risk is not a non-dimensional value but a quantifiable value in terms of probability of health effects, it is necessary to develop approaches to the identification of potential pathology and its recognition at a pathophysiological, preclinical stage.

As a result, in our country, there is a truthfully scientific justification of safe qualitative regulations and application modes for disinfectants in various conditions which in its turn is the basis of the current system of statutory regulation of disinfecting activities [11]. 


\section{References}

1. Briko N.I. The paradigm of contemporary epidemiology. Epidemiology and vaccinal prevention. - 2013, № 6, p. 4-11.

2. Eremeyeva N.I., Kravchenko M.A., Kanischev V.V., Fedorova L.S. The issue of fighting the resistance of various kinds of mycobacteria to disinfectants. Desinfectsionnoe Delo. 2007, № 3. p. 35-39.

3. Zaitseva N.V., Mai I.V., Shur P.Z. Health Risk assessment Today // Healthcare in the Russian Federation. - 2013. - № 2. - p. 20-24.

4. Krasilnikov A.P., Romanovskaya T.R. Microbiological Dictionary-Reference Book. Minsk. Asar. - 1999. 399 p.

5. Onischenko G.G., Popova A.Yu., Zaitseva N.V., Mai I.V., Shur P.Z. Health risk analysis for the purposes of improving sanitary and epidemiological supervision in the Russian Federation. // Health Risk Analysis. - 2014. - № 2. - p. 4-12.

6. Pokrovsky V.I., Briko N.I. Infectious diseases and globalization. Report of the Russian Academy of Sciences. 2010, № 11, p. 6-11.

7. Radiation Hygiene. M.: Publishing House. AT. - 2002. vol.3, p. 608.

8. Resolution of the All-Russian Conference with international participants "Today's Issues of Safety and Health Risk Analysis under Exposure to Environmental Factors" // Health Risk Analysis. 2014. - № 2. - p. 104-107.

9. Shandala M.G. Topical Issues of General Disinfectology. Selected Lectures. M.: Publishing House "Meditsina". 2009. 112 p.

10. Shandala M.G., Zayeva G.N., Maltseva M.M., Pankratova G.P. Methodology of justification of hygienic regulations for disinfectants. // Gigiena i Sanitariya. - 2000. - № 3, - p. 58-61.

11. Shestopalov N.V. Improving disinfecting activities and preventing infectious disease. // Epidemiologiya i Gigiena. - 2013. - № 1. - p. 5-7.

12. Shestopalov N.V., Shandala M.G. Molecular and Biologicl Aspects of disinfectology: current state and future tasks // Desinfectsionnoe Delo. 2013. - № 3. - p.17-21. 